\title{
A IMPORTÂNCIA E O PAPEL DA LITURGIA NO SENSUS FIDEI A PARTIR DO DOCUMENTO DA COMISSÃO TEOLÓGICA INTERNACIONAL: "O Sensus Fidei na Vida da Igreja"
}

\author{
THE IMPORTANCE AND ROLE OF LITHURGY IN \\ SENSUS FIDEI FROM THE DOCUMENTO OF THE \\ INTERNATIONAL THEOLOGICAL COMMISSION: \\ "Sensus Fidei in the Church's Life"
}

Gregório Lutz*

\section{RESUMO}

O autor faz uma análise do documento $O$ sensus fidei na vida da Igreja da Comissão Teológica Internacional do ponto de vista da Liturgia. Por isso, em primeiro lugar, analisa a relação entre ambos para, em seguida, mostrar como a liturgia pode ser fonte para o sensus fidei. Por fim, faz algumas considerações sobre alguns aspectos práticos da vida pastoral da Igreja.

Palavras-chave: Sensus fidei. Comissão Teológica Internacional. Liturgia. Igreja.

\section{ABSTRACT}

The author analyzes the document The sensus fidei in the Church's life of the International Theological Commission from the viewpoint of Liturgy. Therefore, in the first place, it analyzes the relationship between both to show, next, how liturgy can be a source for sensus fidei. Finally, it sets out a few considerations about some practical aspects of the pastoral life of the Church.

Keywords: Sensus fidei. International Theological Commission. Liturgy. Church.

* Rev. Pe. Lecionou Liturgia na Faculdade de Teologia Nossa Senhora de Assunção da Arquidiocese de São Paulo.

\begin{tabular}{|l|l|l|l|l|l|}
\hline Teocomunicação & Porto Alegre & v. 45 & n. 2 & p. 180-192 & maio-ago. 2015 \\
\hline
\end{tabular}




\section{Introdução}

Para alcançar o objetivo do trabalho que a Comissão de Doutrina da CNBB pede ao propor este título, parece ser evidente que se deva primeiro elencar as afirmações que o documento da Comissão Internacional de Teologia faz sobre a liturgia no contexto do sensus fidei. Isso acontecerá numa primeira parte do presente texto. Nesse elenco entrarão também passos do documento que não se referem explicitamente à liturgia, mas nos quais se pode subentender uma relação do sensus fidei com a liturgia. - Todos os textos em questão serão apresentados numa única sequência, a saber, naquela em que aparecem no documento mesmo.

Numa segunda parte do nosso trabalho, apresentaremos um testemunho para ilustrar como, concretamente, pela oração em família e sobretudo pela participação na liturgia, o sensus fidei cresce e amadurece para uma fé refletida e mais objetiva, e até em direção a uma fé sistematizada na teologia.

Uma terceira parte vai trazer mais algumas considerações sobre o sensus fidei em relação à liturgia. Assim se chegará a ter condições para tirar algumas conclusões sobre a importância da liturgia no sensus fidei.

\section{Afirmações do documento sobre relações entre o sensus fidei e a liturgia}

A Comissão Internacional de Teologia vê uma relação do sensus fidei com a liturgia já no primeiro número do seu documento, quando afirma que "todos os batizados participam da função profética de Cristo". De fato, no batismo, numa ação litúrgica, é concedido não somente o dom da fé, mas também a unção de profeta, para ser testemunha da Verdade.

Basicamente, no mesmo sentido, mas bem mais explicitamente, afirma-se, no número 3, que o sujeito individual do sensus fidei é o fiel "que pertence à Igreja pelos sacramentos da iniciação e participa da fé e da vida da Igreja, particularmente por meio da celebração regular da Eucaristia".

Tratando no número 14 das promessas que Jesus fez em seu discurso de despedida, com respeito ao envio e à ação do Espírito Santo, os teólogos dizem: "Tudo isso acontece graças ao dom do Espírito através do mistério pascal, na vida da comunidade cristã, particularmente, na Eucaristia, até a vinda do Senhor". 
No número 16 lemos que a fé "se renova no encontro com o Senhor por ocasião da fração do pão; e ela se alimenta na oração".

Com referência a $H b$ 11,1, afirma-se, no número 45, que "fortificados pelos sacramentos, 'os leigos se tornam heróis poderosos da fé naquilo que se espera"”.

Referindo-se, no número 61, a $1 J_{0} 4,1$, onde o apóstolo escreve que não devemos confiar a todo espírito, mas que devemos ver se os espíritos vêm de Deus, o documento diz que "o sensus fidei fidelis confere ao crente a capacidade de discernir se um ensinamento ou uma prática é coerente com a verdadeira fé".

Nessa, como nas afirmações dos quatro números dos quais trataremos a seguir, o documento da comissão dos teólogos não fala explicitamente da liturgia em relação à fé. Todavia, no ensinamento e na prática que sempre de novo entram em questão, sem dúvida, devese entender, como incluído, o ensinamento que se dá na prática das celebrações litúrgicas.

Aquilo que se diz no número 61 de uma maneira mais geral, especifica-se quando, no número 62, se diz que "o sensus fidei fidelis permite a cada crente perceber uma desarmonia, uma incoerência ou uma contradição entre um ensinamento ou uma prática e a fé cristã autêntica de que ele vive. Ele resiste então ... interiormente, aos ensinamentos ou às práticas em causa, não as aceita ou não toma parte nelas". Não é isso que acontece tantas vezes em nossas comunidades e, precisamente, na prática das celebrações litúrgicas?

No número 63, o documento continua dizendo que "advertidos pelo seu sensus fidei, os indivíduos crentes podem ir até recusar seu consentimento a um ensinamento de seus pastores legítimos, se não reconhecem nesse ensinamento a voz de Cristo, o Bom Pastor... Para Santo Tomás (de Aquino), um crente, mesmo sem competência teológica, pode, e mesmo deve, resistir em virtude do sensus fidei ao seu bispo se este prega coisas heterodoxas".

Ainda nesse contexto, lemos, no número seguinte, que "o sensus fidei fidelis permite também ao crente distinguir na pregação entre aquilo que é essencial para a fé católica autêntica, e aquilo que, sem ser formalmente contrário à fé, é apenas secundário ou mesmo indiferente com respeito ao coração da fé".

Ainda no número 67, os teólogos apresentam uma argumentação em favor do sensus fidei dos leigos; a mesma argumentação pode ser aplicada à relação deste sensus à liturgia. Pois, também e especialmente 
com respeito à liturgia, o Concílio Vaticano II insistiu que os fiéis, por força do seu batismo, têm o direito e o dever de participar ativamente da Liturgia (Cf. SC 14). Vale para esta relação, literalmente, aquilo que o documento diz: Os fiéis "não são somente os destinatários passivos daquilo que a hierarquia ensina e que os teólogos explicam (em nosso caso: o que o clero faz para eles na ação litúrgica); eles são, pelo contrário, sujeitos vivos e ativos no seio da Igreja".

A passagem onde o documento fala mais direta e, ao mesmo tempo, mais explicitamente da relação entre o sensus fidei e a liturgia é, dentro do item 2 do capítulo 3, onde se trata do sensus fidei e o magistério, o número 75: "O vínculo entre o sensus fidelium e o magistério encontrase bem particularmente na liturgia. Os fieis são batizados para um sacerdócio real, que exercem principalmente na Eucaristia, e os bispos são os 'sumos sacerdotes' que presidem a Eucaristia, onde estes também exercem regularmente a sua função de ensinar. A Eucaristia é a fonte e o cume da vida da Igreja. É especialmente aí que os fiéis e seus pastores interagem, como um corpo único em vista de uma meta única: render louvor e glória a Deus. A Eucaristia modela e forma o sensus fidelium, e ele contribui fortemente à formulação e ao afinamento das expressões verbais da fé, porque é lá que o ensinamento dos bispos e dos concílios é, em última análise, 'recebido' pelos fieis. Desde os primeiros séculos do cristianismo, a Eucaristia sustentou a formulação da doutrina da Igreja, porque é aí que se encontra e se celebra de modo mais alto o mistério da fé; e os bispos que presidiam a Eucaristia em suas Igrejas locais, no meio do seu povo fiel, eram também eles mesmos que se reuniam em concílios para determinar como se podia exprimir da melhor maneira a fé em palavras e fórmulas: lex orandi, lex credendi".

Seja permitido observar, neste momento, que esse adágio vale também, de modo geral, para a origem da teologia, entendida como explicação sistemática da fé. Pois, não seria justo considerar as catequeses mistagógicas como as primeiras sistematizações da fé cristã? E estas tinham como base precisamente a liturgia, a oração da Igreja. É evidente, no entanto, que o valor deste adágio não se deve restringir a estas primeiras elaborações de uma teologia sistemática.

Nesse mesmo contexto, podemos ainda lembrar que o Credo, que é uma certa sistematização da fé cristã, tem, desde a suas origens até hoje, seu lugar na liturgia. Ele formula a fé que se celebra, por exemplo, no batismo e na Eucaristia. 
É sabido que o adágio lex orandi, lex credendi também se aplica em sentido contrário, conforme os autores do nosso documento entendem quando escrevem no número 78: "O povo de Deus reconhece intuições ou ideias e as integra na configuração e nas estruturas de sua vida e do seu culto".

No item III do número 82, os teólogos apontam para uma dimensão do sensus fidei que é essencial também para a liturgia: "O sensus fidelium suscita, ao mesmo tempo que reconhece a sua autenticidade, a linguagem simbólica ou mística que se encontra frequentemente na liturgia e na religiosidade popular. ... O teólogo deve efetivamente participar da liturgia da Igreja local, para captar profundamente, pelo coração e não somente pelo espírito, o contexto real, histórico e cultural, no qual a Igreja e seus membros vivem sua fé, e para testemunhar o Cristo no mundo de hoje".

Começando a falar das disposições necessárias para uma participação autêntica no sensus fidei, o documento dos teólogos constata, em seu número 89: "A primeira e mais fundamental de todas as disposições é a participação ativa na vida da Igreja. Uma pertença formal à Igreja não é suficiente. A participação ativa na vida da Igreja significa uma oração constante (cf. 1 Tess 5,17), uma participação ativa da liturgia, especialmente da Eucaristia, uma recepção regular do sacramento da reconciliação".

Reconhecendo que "não é pedido a todos os membros do povo de Deus que estudem cientificamente a Bíblia e os testemunhos da Tradição", os autores do documento sobre o sensus fidei na Igreja dizem no número 93: "O que se exige é bem mais uma escuta atenta e receptiva das Escrituras na liturgia e uma resposta que vem do coração, 'Nós damos graças a Deus' e 'louvor a ti, Senhor Jesus', uma fervorosa profissão do mistério da fé e um 'Amém' que responde ao 'Sim' que Deus diz ao seu povo em Jesus Cristo. A participação na liturgia é a chave para uma participação na Tradição viva da Igreja; e a solidariedade com os pobres e com aqueles que se encontram em necessidade abre o coração para que reconheça a presença e a voz de Cristo".

O documento que estudamos conhece também, além da liturgia ritual, a existencial, quando constata, em seu número 96, que "os sujeitos do sensus fidei são os membros da Igreja que celebram um 'culto racional' e aceitam a função própria da razão iluminada pela fé".

No número 99, lemos: "Uma participação autêntica no sensus fidei requer a santidade. A santidade é a vocação da Igreja inteira e de cada 
crente. ... Uma vida tal é sustentada pelo Espírito Santo, que os cristãos não cessam de invocar e de receber, sobretudo na liturgia".

$\mathrm{O}$ item do documento, ao qual os teólogos deram o título de "o sensus fidei e a religiosidade popular", é especialmente rico no que se refere à importância e ao papel da liturgia ou de atividades semelhantes a ela. Chamo de "atividades semelhantes à liturgia" aquelas expressões de religiosidade ou piedade popular que, no fundo, são celebração do mistério pascal, como a liturgia mesma, por exemplo, as Celebrações da Palavra (sobretudo aos domingos em ausência de um sacerdote ordenado), o Ofício Divino das Comunidades, a Via Sacra, o Rosário ou o Anjo do Senhor. Sem dúvida, são também ou, talvez, em primeiro lugar, estas expressões de religiosidade popular que o documento dos teólogos sobre o sensus fidei tem em mira, quando afirma, nos números 110 e 111: "Enquanto rica diversidade de práticas cristãs, especialmente sob a forma de atividades de culto, como as devoções, as peregrinações e as procissões, a religiosidade popular provém do sensus fidei. ... Tal piedade é uma realidade eclesial suscitada e guiada pelo Espírito Santo. Por ela o povo de Deus recebe verdadeiramente a unção de um sacerdócio sagrado. É natural que o sacerdócio do povo encontra sua expressão numa grande diversidade de formas. A atividade sacerdotal do povo encontra com todo direito seu ponto culminante na liturgia; e é preciso vigiar que as devoções populares 'condigam com a liturgia' (SC 13)".

Lendo assim, como liturgista, o documento da Comissão Internacional de Teólogos sobre o sensus fidei na Igreja, sem dúvida se percebe que grande importância se dá no sensus fidei à liturgia e às demais celebrações do mistério pascal de Cristo e do seu povo.

\section{A Liturgia, "Viveiro" para o Sensus fidei}

\section{Um testemunho}

A liturgia, celebrada em qualquer grau que seja de participação, e o que se assemelha a ela são o ambiente mais profícuo para o sensus fidei, para sua maturação e para sua transformação em fé autêntica ou até em teologia.

Sem menosprezar o ideal de uma participação ativa, consciente, plena e frutuosa, a tese que acaba de ser colocada vale também quando a participação não tem todas estas qualidades em plenitude. Com "o que se assemelha à liturgia”, entendo atividades que são celebração 
do mistério pascal, que a Sacrosanctum Concilium chama de piedosos exercícios (SC 13) e as quais o documento da Comissão Internacional de Teólogos inclui nas expressões da religiosidade popular (n. 107 a 112), a saber, por exemplo, o Rosário, a Via Sacra, o Anjo do Senhor e, com mais razão ainda, o Ofício Divino das Comunidades, e as Celebrações Dominicais da Palavra de Deus.

Ora, a participação dos féis na liturgia não fica, na maioria das vezes ou quase sempre, imperfeita? E a maioria dos fiéis não alimenta, ainda hoje, sua vida espiritual com as devoções?

Parece-me que, em minha vida pessoal e na vida de pessoas com as quais convivi na minha infância, adolescência e juventude, isso se pode observar com nitidez.

Tenho plena consciência de que aquilo que segue, de modo igual ou semelhante, acontece com uma certa frequência e poderia ser dito também de muitas outras vidas e famílias. Portanto, aquilo que vou contar não é nada de extraordinário ou especialmente importante, mas parece que vale a pena fazer esse relato para mostrar e chamar a atenção a fatos comuns da vida que não deveriam ficar despercebidos, sobretudo não em contextos vitais como aquele que está aqui em questão, quando refletimos sobre a relação da liturgia com o sensus fidei.

Não me lembro que meu pai ou minha mãe me tivessem ensinado a fé. Na minha família, ela simplesmente era vivida. Rezamos, sim, sempre antes e depois do almoço e do jantar e, depois destas refeições; rezamos também sempre, ao meio-dia e à noite, o "Anjo do Senhor". Além disso, depois do jantar, com a presença do pai, que na hora do almoço estava na fábrica, nossa oração em comum se estendeu sempre por dez ou quinze minutos. Rezamos geralmente, além do Pai Nosso, da Ave Maria e do Credo, orações a determinados Santos, invocando os santos padroeiros cujos nomes nós e nossos parentes e amigos tinham. Também aos anjos nos dirigimos, sobretudo o anjo da guarda. Por pessoas doentes ou em outras dificuldades rezamos espontaneamente. Nas preces pelos falecidos, mencionamos cada um(a) pelo nome. Sem dúvida, foi sobretudo assim que nasceu em nós crianças, ainda pequenas, a consciência de termos um pai e uma mãe e muitos irmãos também no céu. Desde a idade de poucos anos, o pai nos levou à Igreja, à missa dominical e, mais tarde, também às vésperas ou a uma espécie de celebração da Palavra, na tarde do domingo.

Como lembro, certamente já antes da catequese para a primeira comunhão, eu queria entender muitas coisas de Igreja, de Deus e 
dos Santos. Às vezes, quando meus pais não podiam responder satisfatoriamente a todas as minhas perguntas, eu recorri a um tio, que morava bem perto da nossa casa. Ele tinha querido ser monge cisterciense e tinha já estudado um pouco de teologia, mas depois casou. Na casa dele eu podia admirar toda uma estante cheia de livros.

Da missa, eu participei todos os dias, antes de ir à escola. Durante a semana, ela era, por inteiro, celebrada em latim. Eu lembro que tentei entender palavras latinas que ocorreram sempre de novo, como Deus, Dominus etc. Lembro também que uma vez a professora veio me advertir que não devia cantar junto com o padre o Prefácio ou o Pai Nosso. O serviço de coroinha ajudou muito para o crescimento do meu ser cristão.

Foi, portanto, assim que o sensus fidei, desde o meu batismo, que recebi um dia depois do meu nascimento, cresceu pela oração em família pela participação da missa desde pequeno. Ele amadureceu e, sobretudo, já na catequese de primeira comunhão, se transformou em fé consciente, que mais tarde era um fundamento sólido para o estudo da teologia e uma vida de professor de teologia.

Os meus três irmãos, todos mais novos do que eu, cresceram também assim. Duas irmãs tinham morrido bem pequenas. Tendo terminado os oito anos da escola primária, comecei um aprendizado no escritório de advogados. Dois irmãos se tornaram respectivamente carpinteiro e torneiro mecânico. O mais novo começou a trabalhar na prefeitura. Este sentiu aí a falta de ter feito o segundo grau. Por isso se esforçou para suprir esta lacuna por cursos e estudos supletivos e conseguiu assim fazer uma boa carreira. Todos eles se tornaram membros ativos da Igreja. $\mathrm{O}$ mais novo aprofundou, mais do que os dois outros, seus conhecimentos da doutrina católica, particularmente da doutrina social. Também seus conhecimentos de fé ele aperfeiçoou em cursos e encontros, na Pastoral da Juventude, e na Pastoral Operária. Ele chegou até, sobretudo quando aposentado, a escrever alguns livros.

Assim também em meus irmãos cresceu e madureceu o sensus fidei, principalmente pela constante participação ativa na liturgia e, sem jamais ter tido a oportunidade ou sentido a falta de um estudo sistemático de teologia, a vida deles era e, para o mais novo que ainda está vivo, continua sendo uma vida cristã católica autêntica.

O pequeno mundo do sensus fidei, no qual eu fiz os primeiros passos para conhecer Deus e o evangelho, não teve os limites da minha família, dos meus pais e irmãos. Os primeiros quase oito anos de vida 
vivi na casa do avô materno. Também depois, quando minha família tinha mudado para a casa nova que meus pais construíram no quintal da propriedade do avô, fiquei muito ligado a este, até à sua morte, quando eu tinha dez anos. Sendo ele um grande devoto do Coração de Jesus, eu também aprendi esta devoção. $\mathrm{O}$ avô materno eu não conheci, muito menos o pai dele. Mas, impressionou-me sempre o grande cruzeiro bonito, que meu bisavô com seus dois filhos, dos quais um era o meu avô, ergueu numa das terras dele na beira da estrada, de onde foi mais tarde transferido para a entrada do cemitério do lugar onde nasceu o meu pai. Cada vez que vejo este cruzeiro, ele me fala da fé certamente simples, mas profunda, que meu pai tinha herdado e me transmitiu.

Todos estes parentes e antepassados meus, dos quais ninguém tinha uma escolaridade além do primário de oito anos, tiveram como única escola de fé ou de teologia, além da catequese de primeira comunhão, a missa dominical, que lhes garantiu um sensus fidei cada vez mais sólido e profundo, no qual podiam lutar o bom combate da fé e certamente receber a coroa da glória.

Neste ambiente de fé simples ou de sensus fidei, houve, o que não é de se admirar, muitas vocações de especial consagração. Meu pai e minha mãe tiveram primos padres. Uma irmã do meu pai viveu toda a sua vida como consagrada num convento de freiras. Minha Mãe tinha uma tia freira e também um primo que era irmão religiosos. Em todas as casas vizinhas à casa dos meus pais, com exceção de uma, uma filha ou um filho era ou é ainda padre ou freira. Também estas vocações especiais nasceram quase sempre em jovens que eram membros ativos na comunidade, mas não tiveram formação alguma em teologia. A ninguém deles, porém, faltou, desde pequenos, o sensus fidei.

Evidentemente, este sensus fidei não era uma propriedade somente de indivíduos e famílias, mas das comunidades eclesiais; e ele impregnou toda a sociedade e até a cultura.

Em todos estes ambientes, como sobretudo nos indivíduos, ele nasceu, cresceu e foi sustentado principal ou exclusivamente pela liturgia. E, embora hoje em dia a liturgia seja bem mais compreensível do que antes do Concílio Vaticano II, e também leigos tenham maior facilidade de aprofundar sua fé e até de estudar teologia, a grande maioria do povo de Deus alimenta a sua fé que é antes sensus fidei do que fé consciente e refletida ou teologicamente sistematizada, sobretudo ou exclusivamente pela liturgia. 
Penso que fique evidente por este testemunho que, para os pequenos no Reino de Deus, vale, talvez mais do que para os grandes: Lex orandi - Lex credendi.

\section{Algumas considerações a mais}

\section{O sensus fidei na relação entre religiosidade/piedade popular e liturgia}

Ao tratar do sensus fidei e da religiosidade popular, o documento dos teólogos afirma no n. 111: "A ação sacerdotal do povo encontra corretamente seu ponto culminante na liturgia". Como lemos nos dois primeiros números do documento, a comissão dos teólogos vê o sensus fidei presente nos fiéis batizados. Se assumíssemos a distinção que Paulo VI fez em sua Exortação Apostólica Evangelii nuntiandi (n. 48) entre religiosidade popular e piedade popular, seria conveniente, me parece, ver o sensus fidei sobretudo nas expressões da piedade popular, na qual Paulo VI não vê, como na religiosidade popular, "deformações da religião, como sejam, por exemplo, as superstições". Piedade popular ele chama "de bom grado" a religiosidade do povo, se ela "for bem orientada [...] mediante uma pedagogia de evangelização". Poderíamos, portanto, considerar como piedade popular, no sentido mais pleno, os "piedosos exercícios do povo cristão, conformes com as leis e normas da Igreja [...], de modo especial quando são feitos por ordem da Sé Apostólica" (SC 13). Sem dúvida, o Vaticano II pensou com isso, e certamente em primeiro lugar, mas não exclusivamente, em devoções como o rosário ou a via sacra. Especialmente importante são para nós, neste momento, as últimas palavras do artigo número 13 da Sacrosanctum Concilium, que dizem que "estes exercícios devem ser organizados de tal maneira que condigam com a sagrada liturgia, dela de alguma forma derivem [e] para ela encaminhem o povo". Precisamente, deste final de SC 13, o documento dos teólogos cita uma parte, dizendo que "as devoções populares 'se harmonizem com a liturgia'".

Aparece aqui no documento dos teólogos o que se observa na vida cristã, o que também pude mencionar no meu "testemunho" acima: A piedade popular é expressão do sensus fidei, e isso numa medida maior e mais intensa, quanto mais as devoções são celebração do mistério que celebramos na liturgia, como é o caso de maneira exemplar em devoções como o Rosário, no qual se contemplam os mistérios da encarnação, da paixão e da glorificação do Senhor. O mesmo se pode dizer, por 
exemplo, da oração do Angelus. Nestes dois casos, até a forma da oração alude à própria liturgia: As 150 Ave-Marias do Rosário, aos 150 salmos que se rezam sobretudo na liturgia das horas; as horas em que se reza o Angelus, às laudes, à oração do meio dia e as vésperas. Portanto, estas e muitas outras devoções populares, pelo menos um pouco todas elas, são participação da oração oficial da Igreja; oração, portanto, que é expressão da fé autêntica cristã. E, quanto mais se aproximam estes exercícios de piedade popular (ou se preferimos dizer, de religiosidade popular), em conteúdo e forma da própria liturgia, tanto mais se desenvolve por meio deles o sensus fidei em direção à fé cristã consciente e autêntica.

\section{Sensus fidei de não batizados}

No item anterior, sobre os sensus fidei na religiosidade ou piedade popular, refletimos quase exclusivamente sobre expressões da piedade popular, que é "orientada [...] mediante uma pedagogia de evangelização" (EM 48), e não sobre a religiosidade popular que tem "suas limitações" e se acha "frequentemente aberta à penetração de muitas deformações da religião" (ibidem).

No entanto, o liturgista pode interessar-se também pelas pessoas não cristãs, portanto, pessoas não batizadas, por exemplo judeus, ou adeptos de outras religiões não cristãs que celebram igualmente seus cultos e leem as suas escrituras sagradas, e ele pode perguntar se também elas têm o sensus fidei que possa ser base ou aliado para um crescimento rumo à fé da Igreja, especialmente pela sua participação em seus cultos não cristãos, nos quais podem estar presentes sementes do Verbo. $\mathrm{O}$ Espírito Santo não está presente também neles? Estes Semina Verbi ou a possibilidade do homem de conhecer pelas criaturas o seu criador (cf. $R m$ 1,19-20), não seriam também sensus fidei? A resposta deve ser "não", porque os não batizados que não receberam o dom da fé, também não possuem este instinto sobrenatural do sensus fidei, que está essencialmente ligado à fé da Igreja. Evidentemente, com este "não" não se nega a possibilidade da presença e ação do Espírito Santo "que enche o universo" (Sb 1,7).

\section{O sensus fidei nos cristãos não praticantes}

Está crescendo nos países com tradição católica e cristã o número dos cristãos batizados na infância, mas que nunca ou pelo menos deste que chegaram à adolescência ou à idade adulta, não praticaram a fé que lhes foi infusa no batismo, participando da vida eclesial, particularmente 
da liturgia. Igualmente, há sempre mais crianças que não são batizadas ou cujo batismo é adiado para uma idade em que elas mesmas podem decidir se querem ser batizadas ou não. Os pais de muitas destas crianças são batizados, mas frequentam uma igreja apenas na noite de Natal ou por ocasião de um casamento ou de uma missa de sétimo dia. Nestes casos, ou quando fazem com sua paróquia a romaria anual a Aparecida, levam consigo também os seus filhos. Mas, além disso, não praticam o seu ser católico e cristão e não providenciam nenhuma iniciação dos seus filhos a uma vida cristã e católica e, muito menos, à oração ou à liturgia. Os padres que presidem as celebrações destes casamentos e as missas de sétimo dia, também os padres que acolhem os romeiros em Aparecida e celebram com eles, geralmente estão conscientes de que nestas oportunidades devem levar em consideração especial estes cristãos não praticantes que são também membros da Igreja. Não se duvida de que o sensus fidei possa crescer naqueles que são batizados, se eles se sintonizam com o mistério que é celebrado. Mas seus filhos não batizados, que talvez poderíamos considerar como em estado de catecumenato e que, assim participam junto com seus pais de tais celebrações, ficariam excluídos do dom da fé e do sensus fidei que poderia assim neles ser despertado ou crescer?

Deixando agora de lado especulações sobre casos duvidosos de existência e, por conseguinte, a relação do sensus fidei com liturgia, guardemos que para batizados não praticantes, que só esporádica e, portanto, rarissimamente participam de uma celebração litúrgica, isso é uma oportunidade para o crescimento e amadurecimento de sua fé. Mas também para os não batizados a participação em celebrações litúrgicas seria uma boa oportunidade de se abrirem para a presença e ação de Deus, que quer infundir seu Espírito "sobre toda carne" (At 2,17).

\section{$4 \quad$ O sensus fidei na pastoral litúrgica}

Em nenhum campo da vida e ação da Igreja os fiéis fazem tanto uso "[d]o direito e, às vezes, até [d]o dever de manifestar aos pastores sagrados a própria opinião sobre o que afeta o bem da Igreja" (120), como na liturgia, sobretudo quando está em questão a integridade da fé cristã autêntica nas celebrações litúrgicas. E não podemos ignorar respostas da parte dos pastores que vão na direção daquilo que um dos meus sucessores como pároco disse a uma coordenadora de comunidade: "Você não sabe que sou um homem de Deus, o seu senhor? Eu sei o que é para fazer e não preciso do conselho de ninguém". 
Como é mais fraterna a vida na comunidade, quando o padre respeita e leva em consideração o sensus fidei dos fiéis, a opinião deles, especialmente nas coisas práticas da comunidade ou paróquia, e até em questões de fé! E caso ele não concorde com uma opinião ou proposta impertinente dos fiéis, mas explica com calma e utilizando argumentos pertinentes do porquê de não poder concordar, os fiéis acabam aceitando uma proposta ou solução melhor. Infelizmente e sobretudo na pastoral litúrgica, e particularmente na preparação das celebrações ou em cursos e reuniões de formação dos agentes litúrgicos leigos, é comum haver queixas de que suas observações críticas e ideias ou propostas pertinentes não são aceitas pelos ordenados. Em muitos destes casos, sem dúvida, despreza-se assim o sensus fidei.

\section{Conclusão}

Levando em consideração as afirmações da Comissão Internacional de Teologia em seu documento sobre o sensus fidei, assim como o meu testemunho pessoal e as considerações ulteriores sobre o sensus fidei na liturgia, chego à conclusão de que o sensus fidei, i. é, o "instinto pela verdade do evangelho, que [...] permite reconhecer quais são a doutrina e a prática cristãs autênticas e a elas aderir" (n. 2), pode levar os batizados, desde a sua infância, a rezar e a participar da liturgia da Igreja. Do outro lado, pela oração e a participação na liturgia, cresce e amadurece no cristão o sensus fidei, recebido com o batismo, em direção a uma fé sempre mais explicita e autenticamente cristã.

Este caminho, porém, de chegar a uma fé madura e sistematizada que, a partir do Evangelho, nos é proposto pela Igreja, não é o único e exclusivo que leva à santidade. Mesmo que não se chegue, a partir de uma religiosidade ou piedade popular, a uma fé explícita nos moldes do catecismo, como era amplamente o caso no Brasil e na América Latina dos séculos passados, o sensus fidei pode ser uma base firme e suficiente para uma vida autenticamente santa e cristã.

No entanto, embora todo caminho de chegar à santidade seja íngreme, caminhando na luz plena da fé que a Igreja nos propõe, especialmente na liturgia, a caminhada da vida leva mais fácil e seguramente em direção à plena visão da luz eterna, à casa do Pai. 